\title{
¿Para qué necesitamos la herencia clásica?
}

\section{György Lukács}

\section{Nota del traductor}

El siguiente artículo de Lukács fue escrito en el contexto del asíllamado "debate sobre el expresionismo" y con posterioridad a enero de 1938, pues el diálogo de Ernst Bloch y Hans Eisler con el que polemiza apareció publicado el seis de ese mes en Die neue Weltbühne (La nueva escena mundial). Se trata de la breve pieza "Die Kunst zu Erben", que puede significar tanto "el arte de heredar" como "el arte para heredar". En aquel breve trabajo, un "amateur del arte" y un "productor de arte" -que respectivamente coinciden, más allá del artificio literario, con los personajes históricos de Bloch y Eisler-imputan a György Lukács un dogmatismo clasicista e intentan refutar tal enfoque discutiendo acerca de no solo qué elementos heredar de la cultura burguesa en la lucha contra el fascismo, sino también de cómo llevar a cabo tal herencia. Al igual que otros documentos de tal debate, la respuesta de Lukács permaneció inédita hasta 1984, cuando fue incluida por Miklós Mesterházi y György Mezei en su edición de Ernst Bloch und Georg Lukács. Dokumente zum 100. Geburtstag (Ernst Bloch y Georg Lukács. Documentos en el centenario de sus nacimientos. Budapest, MTA Filozófiai Intézet, Lukács Archívum, 1984). Aquí se presenta en español por primera vez. ${ }^{3}$ Todas las notas son del traductor.

\footnotetext{
1 Traducido del alemán por Francisco García Chicote.

2 Una traducción en lengua portuguesa de este diálogo aparece en la segunda -y ampliada- edición de la obra de Carlos Eduardo Jordão Machado Debate sobre o expressionismo, que se reseña en este número de Inter Litteras. y el ensayo "Crítica de la derecha y crítica de la izquierda", fueron publicados recientemente en español en las revistas Cerrados, de la Universidad de Brasilia, y Signotica, de la Universidad Federal de Goiás, y se encuentran disponibles en línea.
} 
El artículo de Ernst Bloch y Hans Eisler plantea una serie de cuestiones actuales muy importantes sobre las que yo también tomaría posición, si con ello los autores no me hubieran hecho el honor de hacer de mí el representante de un academismo ecléctico. ${ }^{4}$

Una discusión sobre la herencia clásica perfectamente puede ser fructífera, dado que, en lo esencial, estoy de acuerdo con la conclusión a la que llega, en el diálogo, el amateur del arte, "que el presente ha de ser atendido críticamente y considerado en todas sus formaciones de transición”. Se trata únicamente de cómo ha de ser entendida esta frase. Y ciertamente se acordará Ernst Bloch que en el curso de las últimas décadas tuvimos varias discusiones muy agudas y fructíferas, precisamente sobre la base de un acuerdo en las metas generales y sobre la base de divergencias de principio en la concretización de aquellas.

Para ello deben empero primero crearse las bases de una discusión, alcanzarse un nivel teórico determinado, alcanzarse una determinada lealtad en la reproducción de la opinión contrapuesta. No puedo creer que Ersnt Bloch esté de acuerdo con la opinión del productor acerca de la herencia clásica. Este alude correctamente a la manifestación en Berlín por la función de Don Carlos, ${ }^{5}$ pero agrega a mi entender de manera muy incorrecta que: “¿En qué consiste nuestra tarea fuera de Alemania? Es claro que solamente debemos ayudar a seleccionar y preparar el material clásico que sea adecuado para tal lucha" (el énfasis es mío). La herencia clásica consiste, entonces, de acuerdo con el productor, en una colección preparada de citas que contenga pasajes incómodos para los fascistas, pero difíciles de prohibir desde el punto de vista legal. La herencia clásica es pues un Büchmann antifascista. ${ }^{6}$ Es muy lamentable para el nivel de la discusión que el amateur del arte no haya discutido ni siquiera someramente tales opiniones. Y de esta manera parece como si esta fuera la concepción de ambos autores sobre la herencia clásica.

En lo que concierne a la fidelidad en la reproducción de mis opiniones, me remito solamente a un único pasaje, porque este posee una importancia de principio, aclaradora de la discusión. El amateur del arte del diálogo me adjudica la concepción, como si yo considerase a Flaubert o Zola como escritores de "menor calidad" que los “escritores desconocidos de la Revolución Francesa”. Ahora bien, en primer lugar nunca hablé de una "menor calidad” de la escritura de Flaubert

4 El productor del arte dice, remitiéndose a aquellos que defienden la tesis imputada a Lukács que "en Europa occidental [...] la lucha contra el sociologismo [=la lucha contra la idea de que la conciencia política del artista es determinante para el valor estético de su obra; FGCH] se ha convertido en un eclecticismo no menos esquemático, una carencia acrítica de discriminación, que ve clásicos en todos lados" (Bloch y Eisler, 1973: 259).

5 Dice el productor: "Es por cierto de la mayor importancia para los antifascistas, al interior de la Alemania actual, interpretar los clásicos permitidos en un sentido revolucionario. Una aprobación al conocido pasaje de Don Carlos ofrece la posibilidad de manifestarse legalmente contra la opresión de la libertad de pensamiento" (1973: 259).

6 Lukács se refiere aquí a la por entonces muy conocida antología de frases hechas de Georg Büchman Geflügelte Worte (palabras corrientes), de 1864.

7 Se lee de Bloch: "Tal como ya hice notar al principio, Lukács equipara sin más el fin del ascenso de la clase burguesa en el siglo XIX con el comienzo de su caída artística. ¿Pero son escritores franceses como Flaubert, Zola, Verlaine, a pesar de que no fueron paridos por la clase en ascenso, realmente de menor calidad que los escritores desconocidos de la Revolución Francesa?" (1973: 261). 
o Zola. Los describí como figuras trágicas, que en las heroicas luchas están, en el plano artístico, por debajo de las inclemencias de su época. En segundo lugar, nunca los comparé con poetas desconocidos de la Revolución Francesa, sino con las grandes manifestaciones culminantes del realismo moderno: con Goethe o Walter Scott; con Balzac o Tolstoi. Si expusiera las opiniones de Bloch con la misma fidelidad, podría decir: de acuerdo con Bloch, uno debería criticar fuertemente a Sófocles y Shakespeare, Goethe y Schiller, etc.; por el contrario, sería falso pronunciar una palabra de crítica sobre Picasso, Dos Passos o Brecht. Estoy muy a favor de que no deberíamos discutir en un nivel de este tipo.

Pero la cuestión misma posee una gran importancia de principio. El amateur del arte introduce la significancia de Richard Wagner y agrega muy correctamente que "la tríade Haydn, Mozart, Beethoven no se repitió más". Nadie niega que Wagner sea "la mayor manifestación musical después de Beethoven". Se trata empero de -y este es también el núcleo del problema de Zola o Flaubert- ¿qué aspecto de una tal muy compleja y significativa manifestación es importante para la cultura actual? ¿La magnitud del talento o la problematicidad trágica, históricamente necesaria de las obras? Ese es el verdadero núcleo de una discusión sobre las grandes figuras de transición del siglo XIX.

Lamentablemente, para Bloch esta cuestión parece estar decidida antes de la discusión. Reconoce de manera formal y abstracta la problematicidad en Wagner, pero no extrae de esta constatación ninguna consecuencia. De ello resulta una concepción muy unilateral y estrecha acerca del arte del presente. Cuando Bloch habla del arte actual, este se halla representado en él exclusivamente por figuras como Picasso, Dos Passos y Brecht. Ni con la más mínima alusión son referidos los realistas significativos de nuestros días, Gorki o Romain Rolland, Thomas Mann o Heinrich Mann. ¿No son estos artistas importantes, actuales y contemporáneos? ¿Radica la corriente progresista en el arte actual exclusivamente en la destrucción consciente de las viejas formas, tal como conscientemente llevan a cabo Dos Passos en la épica, Brecht en el drama? ¿Está realmente pasado de moda el gran arte narrativo "tradicional” de los Gorki, Rolland o Thomas Mann? ¿No tiene ninguna significancia actual para nosotros una tal obra maestra como el fragmento de novela de Thomas Mann publicado en el primer número de Mass und $W e r t^{8}$ ? ¿Acaso no arraiga realmente esta narrativa, no solo en el plano artístico, sino también en el de las grandes tareas democrático-culturales del Frente Popular, más profundamente que los experimentos de destrucción formal? En una palabra: ¿son solamente los adversarios del realismo los representantes autorizados del arte de hoy?

Con esto llegamos, creo, a la cuestión crucial de nuestras diferencias de opinión. Como ve el lector, está lejos de mí desestimar en bloque el arte de hoy. Meramente critico en él las corrientes antirrealistas que son aún hoy muy fuertemente eficaces. Y la toma de posición a favor o en contra del realismo no es de ninguna

8 Medida y valor. Se trata de una publicación periódica dirigida por Thomas Mann y Konrad Falke que apareció entre 1937 y 1940. Lukács se refiere a Lotte en Weimar, de Thomas Mann. 
manera una mera “cuestión de gusto". Se relaciona más bien con las más importantes cuestiones culturales de la época.

La inhumanidad, cuyo cénit vemos en los países fascistas, no impactó en nuestra realidad como un rayo proveniente de un cielo despejado. El cielo de la humanidad, del humanismo, ya hacía tiempo había dejado de estar despejado. La inhumanidad surgió de la esencia de la sociedad capitalista y creció de manera paralela con el crecimiento de esta. Naturalmente, solo los peores literatos se complacieron con tal desarrollo; solo los peores literatos o negaron o embadurnaron con lindos colores este desarrollo. Todos los escritores significativos a partir de la segunda mitad del siglo XIX combatieron con todos sus medios ideológicos y artísticos contra esta inhumanidad que amenazaba con devorarlo todo. La pregunta es solamente cómo fue combatida.

Los que contribuyen a la Weltbühne con artículos se entusiasman con razón con la lucha de los marxistas rusos contra la sociología vulgar. Pero han dejado de lado totalmente en sus artículos una conquista esencial de esta lucha. Esta es el punto de vista de que el enfoque político o ideológico de un escritor a favor o en contra de un sistema social determinado no ofrece aún ninguna garantía para que su configuración de esta sociedad sea profunda y realista [lebenswahr]. No siempre son los escritores más progresistas en el plano político los que dan las imágenes más realistas [lebenswahrste] de una época. El realista legitimista Balzac ha criticado artísticamente la restauración más profundamente que sus contemporáneos liberales o republicanos.

Aplicado a nuestra cuestión, esto significa tanto como: desde el punto de vista artístico se trata en primera línea de cuán enérgicamente un escritor, en tanto configurador de hombres, va contra la corriente de la inhumanidad capitalista, de la fragmentación y el sofocación del hombre. Pues es totalmente posible que escritores combatan de manera muy radical las tendencias reaccionarias en el plano de la política y la crítica social, pero en esta cuestión decisiva acompañen todas las tendencias artísticas inhumanas y enemigas del hombre. Y por el otro lado hay escritores que en lo político no son por mucho tan radicales, pero en esta cuestión se oponen de la manera más contundente a las corrientes barbáricas de la época. Basta con remitirse a Thomas Mann para ver claramente esta contraposición en nuestra literatura actual. En la oposición humanista-artista contra aquella barbarie de la época que culmina en el fascismo, es Thomas Mann mucho más radical, decidido y consecuente que cualquier Brecht o Dos Passos. Y esta diferencia se expresa en el plano artístico precisamente en la posición al realismo. No solamente en el abstracto a favor y en contra, sino ante todo en el cómo de la forma de configuración realista.

No se trata aquí de la magnitud del talento. Brecht es un escritor extraordinariamente talentoso. Pero contémplese qué ha hecho de la maravillosa, humanamente madura y profunda obra de Gorki La madre. En Gorki, un pueblo subyugado, oprimido, inhumanamente pisoteado toma conciencia de un humanismo combativo. El surgimiento de las perspectivas revolucionarias es a la vez el nacimiento 
de hombres ricos, multilaterales y polifacéticos, y sin embargos unitarios. La maduración de la claridad teórica y política acerca del accionar revolucionario es a la vez el despertar de aquellas enormes energías humanas, que existen en el pueblo y cuyo desencadenamiento no solo posibilita la revolución, sino que a la vez asegura la conducción superior del desarrollo cultural de la humanidad como consecuencia de y de acuerdo con la revolución. A partir de esta imagen profunda y rica en perspectivas, Gorki se convirtió en Brecht en una clase de agitación áridamente dialogizada acerca de determinadas tesis, seleccionadas de El capital y de la táctica comunista. En la configuración humana, Brecht se ha supeditado a aquellas tendencias del desarrollo moderno que toleran la sofocación de toda humanidad, el convertirse del hombre en fetiche abstracto, en número abstracto en tanto resultado acabado, en tanto "destino". Naturalmente sé que Brecht es, en tanto hombre, en tanto político, un adversario apasionado de este desarrollo. Pero toda la teoría y praxis de su dramaturgia "antiaristotélica" consiste en el reconocimiento dogmático, acrítico de este estado de las cosas.

No se crea que aquí meramente se trata de la lucha de corrientes artísticas, de "cuestiones de gusto". Es un gran mérito de Ernst Bloch el haber criticado tan agudamente en su Herencia de este tiempo la estrechez de la literatura de izquierda, el haber indicado que de tal manera nunca podrán ser movilizadas las amplias masas del pueblo para la lucha contra el fascismo. Pero esta estrechez no es meramente un asunto del contenido y de la forma de la agitación política en sentido estricto. También las bellas letras pueden ser -precisamente en su dación de forma, en su modo de configuración- estrechas o amplias y profundas, populares o meramente interesantes desde el punto de vista de atelier. La cuestión de la anchura y profundidad de la configuración humana no es por lo tanto ninguna "cuestión de gusto", sino un problema cultural tan acuciante, que se traspone inmediatamente a lo político. Solamente una literatura que pueda conmover y cautivar a las más amplias masas con su configuración humana ejercerá también en lo político un efecto de masa sacudidor.

La lucha por una literatura tal es una cuestión central del Frente Popular. No avanzaremos un paso mientras meramente llenemos los viejos clichés literarios con consignas del Frente Popular. Por el contrario, una figura como la de Enrique IV de Heinrich Mann significa un paso adelante muy grande. Pues allí, a pesar de la distancia especial y temporal de nuestras actuales cuestiones del día, ha sido caracterizado de manera rica y viva aquel hombre que en el curso de nuestra lucha contra el fascismo debe y habrá de emerger, aquel tipo humano del humanismo consciente del Frente Popular que supera definitivamente el fascismo. No se trata aquí de si concuerdo cien por ciento con el modo de configuración de Heinrich Mann o si me encuentro parcialmente crítico respecto de ella. Se trata de ver qué significa este realismo, significativo y que cala hondo, para el Frente Popular en lo cultural y político.

Y de esta manera llego a la cuestión de los clásicos. ¿Por qué los clásicos (los verdaderos clásicos) son para nosotros importantes, actuales, incluso me arriesgo a decir la palabra: modélicos? Obviamente, no en el sentido de que un escritor 
debiera hoy intentar escribir como Goethe o Tolstoi. Eso es un sinsentido pueril. Pero los clásicos nos ofrecen un parámetro y un modelo de cómo una humanidad rica y profunda puede ser configurada de manera rica y profunda y conmovedora. Nuestros contemporáneos perdieron-apresados en los prejuicios barbáricos del período imperialista- casi toda escala de la verdadera configuración humana. Consideran como la quintaesencia tipificadora de la realidad o bien la acumulación de detalles superficiales e indiferentes o bien una esquemática abstracta. El extraordinario efecto progresista y educativo de escritores tales como Gorki y Rolland, como Thomas y Heinrich Mann radica precisamente en el hecho de que en esta cuestión vital decisiva de la literatura han combatido decididamente toda su vida las tendencias inhumanas y antiartísticas de su época; en el hecho de que a través de su obra vital se agita el aún grande, vivo y liberador espíritu del período clásico.

Todas las así llamadas cuestiones formales de la literatura clásica están relacionadas con esta cuestión vital de la literatura. Por esta razón son para nosotros interesantes y actuales. El descubrimiento de algunas relaciones de este tipo fue la intención de mis ensayos de teoría literaria e historia de la literatura. Bloch sabe cuánto yo considero estos ensayos como primeras aproximaciones para la elaboración de un ámbito que tiene que ser nuevamente conquistado y cuánto espero de una discusión genuina sobre estos problemas incluso para mi propio desarrollo. Pero deberían ser discutidos y criticados los problemas mismos, y no el espantajo de un academismo ecléctico, que solo sirve para asegurarles una posición monopólica como único arte moderno a los jugueteos formales decadentes.

Ernst Bloch, un conocedor y amante de la literatura y el arte populares, debería una vez reflexionar sobre el carácter de atelier de aquellas corrientes artísticas que él hoy tan decididamente defiende y sobre el carácter popular del arte clásico. Sé muy bien que la mayor parte de los clásicos no defendió opiniones radicales ni política ni socialmente. Su carácter popular radica en el hecho de que han percibido profundamente y descrito de manera apasionante las extraordinarias energías humanas, que existen permanentemente en el pueblo, que precisan solamente de una ocasión desencadenante para intervenir de manera productiva y reconfiguradora en la vida de la sociedad. Y es la tarea mayor, la más actual, de la literatura de hoy del Frente Popular es observar atentamente el despertar de estas fuerzas en el pueblo alemán, subyugado por el fascismo, y configurarlas de manera tan apasionante, que la imagen configurada se convierta en modelo acelerador para las masas populares. Tal vez sonará para algunos lectores paradójico, pero me arriesgo sin embargo a pronunciarlo, que toda nuestra literatura contemporánea -con la única excepción de Gorki- no ha producido ninguna figura popular que pueda ser comparada con Klärchen o Dorothea, de Goethe, con Jenny Deans, de Walter Scott, con Leatherstocking, de Cooper, e incluso con innumerables figuras de la literatura clásica.

Esto tenemos que aprender de los clásicos. Esta es la parte más importante de su herencia. De este modo y no meramente mediante citas seleccionadas, 
momentáneamente utilizables, se convierten ellos en nuestros poderosos aliados en la lucha contra el barbarismo, enemigo del pueblo, que es el fascismo. Sobre esta función de la literatura clásica podemos y debemos discutir. Pero frases ligeras como "depósito de mercancía cultural, del cual se extraen recetas abstractas"9 no ayudan para nada en esta discusión. 


\section{Q Bibliografía}

" Bloch, E. y H. Eisler. (1973). Die Kunst zu Erben. En Schmitt H-J. (ed.). Die Expressionismusdebatte. Materialien zu einer marxistischen Realismuskonzeption, pp. 258-263. Frankfurt a.M.: Suhrkamp. 